\title{
Comparative Evaluation on the Effect of Zinc-Probiotic and Zinc Therapy in Pediatric Acute Gastroenteritis
}

\author{
Md. Anwarul Azim ${ }^{*}$ \\ Badrud Doza ${ }^{1}$ \\ Shahed lqbal ${ }^{1}$ \\ Farah Chowdhury ${ }^{1}$ \\ Sanjoy Kanti Biswas ${ }^{2}$
}

'Department of Pediatrics

Chattogaram Maa-O-Shishu Hospital Medical College Chattogram, Bangladesh.

${ }^{2}$ Department of Microbiology Chattogaram Maa-O-Shishu Hospital Medical College Chattogram, Bangladesh.
*Correspondence to:

\section{Dr. Md. Anwarul Azim}

Assistant Professor

Department of Pediatric Gastroenterology

Chattogram Maa-O-Shishu Hospital Medical College

Chattogram, Bangladesh.

Mobile : +8801974357224

Email: aazim020972@gmail.com

Date of Submission : 20.10 .2019

Date of Acceptance : 10.01 .2020

\begin{abstract}
Background: Acute watery diarrhea in under 5 children is still a major health burden worldwide despite all available efforts that have been made to reduce its incidence and prevalence. Mortality rate is still high among under 5 children. Therefore, appropriate and comprehensive management of diarrhea is essential. There are lot of studies on the role of zinc and probiotic in reducing the duration and severity of acute watery diarrhea. This study emphasized on compared effect of using a combination zinc-probiotic and zinc in pediatric acute gastroenteritis.
\end{abstract}

Materials and methods: This was a randomized controlled trial type study, conducted at Department of Pediatric Gastroenterology at Chattogram Maa-OShishu Hospital Medical College from November 2018 to March 2019. A total of 100 numbers of children ages 3 months to 5 years with acute watery diarrhea were enrolled those who were fulfilled the selection criteria. They were divided into two groups. Group $A(n=50)$ received zinc-probiotics combination therapy and group $B$ $(n=50)$ received zinc only. Measurement of disease severity was based on the frequency of diarrhea (Times/day) and duration of diarrhea (Hours) after initial drug consumption.

Results: Among the study population $63.5 \%$ male \& $32.7 \%$ female in group $A$ and $56.4 \%$ male \& $34.5 \%$ female in group $B$. Duration of acute watery diarrhea was significantly reduced in group $A$ than group $B(56.4$ hours versus 70.80 hours respectively). We also observed significant difference in length of hospital stay in Group A and Group B (68.16 hours vs 83.04 hours) respectively.

Conclusion: Combination therapy was more effective in reducing the severity of acute watery diarrhea than zinc alone therapy in under 5 children.

Key words: Acute watery diarrhea; Zinc; Probiotic; Outcome.

\section{INTRODUCTION}

Diarrhea remains the second leading cause of death among children 1-59 months of age $^{1}$. Currently, WHO recommends treatment with Oral Rehydration Salts (ORS) and continued feeding for the prevention and treatment of dehydration, as well as zinc to shorten the duration and severity of the episode ${ }^{2}$. Probiotics are not recommended by WHO for the treatment of community-acquired acute diarrhea, though they are becoming increasingly popular in some countries ${ }^{3}$.

Probiotics are non-pathogenic live microorganisms. When ingested, probiotics can survive passage through the stomach and small bowel ${ }^{4}$. They compete with enteric pathogens for available nutrients and bacterial adhesion sites, increase the acidity of the intestinal environment, synthesize compounds that destroy or inhibit pathogens, and may stimulate the host's immune response to invading pathogens $\mathrm{s}^{4,5}$. 
The use of probiotic nonpathogenic bacteria for prevention and therapy of diarrhea has been successful in some settings although the evidence is inconclusive to recommend their use in all settings ${ }^{6}$. Benefits of probiotics on diarrhea in children may be strain and/or etiology specific ${ }^{7-8}$.

Diarrhoea is more common in children with zinc deficiency and responds quickly to zinc supplementation. Zinc has a direct effect on intestinal villous, brush border disaccharides activity and intestinal transport of water and electrolytes. Zinc also has a marked effect on $\mathrm{T}$ cell function and its supplementation improves immunity. Thus it may also reduce the severity of diarrhea $^{9-10}$.

Zinc administration for diarrhea management can significantly reduce all cause mortality by $46 \%$ and hospital admission by $23 \%{ }^{6}$. A study of ICDDRB on Zinc supplementation in children with cholera in Bangladesh reveals that more patients in the zinc group than in the control group recovered by two days $(49 \%$ v $32 \%, \mathrm{p}-0.032)$ and by three days ( $81 \%$ vs.68\%, p$0.03)$. Zinc supplemented patients had $12 \%$ shorter duration of diarrhea than control patients (64.1 vs. 72.8 h, P-0.028) $)^{11}$. Zinc supplementation during acute diarrhoea is currently recommended by the World Health Organization and $\mathrm{UNICEF}^{12}$.

So, we expect that combined therapy with zinc and probiotics will be more efficacious than zinc therapy alone. In this context our study is justifiable.

\section{MATERIALS AND METHODS}

We conduct an open, randomized, controlled trial from November 2018 to March 2019, in the Pediatric Diarrhoea Ward of Chattogram Maa-O-Shishu Hospital, Chattogram. We included children aged 3 months to 5 years with acute diarrhea. We excluded those with severe malnutrition, encephalitis, meningitis, sepsis, bronchopneumonia, immunocompromised state or stool culture positive cases. Subject were divided into two groups by simple randomization using random table. Group A received zinc sulfate $10 \mathrm{mg}$ /day for age $<6$ month and $20 \mathrm{mg} /$ day $>6$ month and probiotics two times orally for 10 days. Group 2 received zinc sulfate at the same dose as group B. The probiotics were mixed into milk or boiled water. Both doctor and parents were aware of the therapies given.

We did stool examination, stool culture positive cases excluded from study. Clinically the causes of diarrhea was distinguished by the stool consistency. Dysentery was characterized by acute diarrhea mixed with blood. We suspected cholera if symptom occurred during known diarrheal outbreak involving children and adults or frequent, voluminous, loose stool quickly led to severe dehydration with hypovolemic shock or severe dehydration occurred and antibiotics shortened the duration of diarrhea.

Monitoring of the duration and frequency of diarrhea was done during hospitalization on daily follow up, number of stool passed with consistency was recorded and sign of dehydration

was assessed. Presence of fever, vomiting toxicity and side effects relating to the administration of zinc and probiotic were also observed. We defined recovery from diarrhea as stool passed $<3$ times with normal consistency. Home monitoring was done by contacting the parents or caregiver by mobile phone.

We used SPSS version 16 for data analysis. Independent t-test was used to assess the relationship between zinc-probiotic combination therapy and zinc alone as nominal scale with the duration and frequency of diarrhea as numerical scale. Difference were considered significant at a probability value of $\mathrm{p}<0.05$ and $95 \%$ CI. Our studyisan intention to treat analysisbased study.

\section{RESULTS}

There were 100 children who met the inclusion criteria. We divided them into two groups of 50 subject each: those who received zinc-probiotic combination therapy (Group A) and those who received zinc therapy alone (Group B)

Table I : Baseline characteristics

\begin{tabular}{|c|c|c|}
\hline \multirow[t]{3}{*}{ Characteristics } & Group A & Group B \\
\hline & Zinc-Probiotics & Zinc \\
\hline & $\mathrm{n}=\mathbf{5 0}$ & $\mathrm{n}=\mathbf{5 0}$ \\
\hline
\end{tabular}

\section{AGE (Month)}

Mean age $\pm \mathrm{SD}$ in month

3 month to 6month

6 month to 24 month

24 month to 59 month

Mean frequency of diarrhoea

before treatment, times/day

Mean duration of diarrhea

before treatment

Weight (Kg)

Male

Female

Breast feeding during 1st 6 month

Exclusive breast feeding

Formula feeding

Mixed feeding

Water supply

Tube well water

Supply water

Mothers education

Above SSC

Below SSC

Knowledge about ORS

preparation of mother

knows

Dosen't know

Dehydration status

No sign of dehydration

Some dehydration
$39(75 \%)$

$11(21.2 \%)$

$\begin{array}{rr}11.86 \pm 6.5 & 11.79 \pm 5.98 \\ 7(13.5 \%) & 10(18.2 \%) \\ 40(76.9 \%) & 37(67.3 \%) \\ 3(5.8 \%) & 3(5.5 \%)\end{array}$

$10.93 \pm 10.27 \quad 12.25 \pm 10.35$

$58.4 \pm 18.67 \quad 52 \pm 23.5$

$8.21 \pm 2.6 \quad 8.09+\_2.79$

$33(63.5 \%) \quad 31(56.4 \%)$

$17(32.7 \%) \quad 19(34.5 \%)$

$31(59.6 \%) \quad 32(58.2 \%)$

$6(11.5 \%) \quad 1(1.8 \%)$

$13(25 \%) \quad 17(30.9)$

$22(53.8 \%) \quad 20(36.4 \%)$

$28(42.3 \%) \quad 30(54.5 \%)$

$39(75 \%) \quad 13(23.6 \%)$

$11(21.2 \%) \quad 37(67.3 \%)$

$42(76.4 \%)$

$8(14.4 \%)$

$10(20 \%) \quad 16(29.1 \%)$

$40(80 \%) \quad 34(61.8 \%)$ 


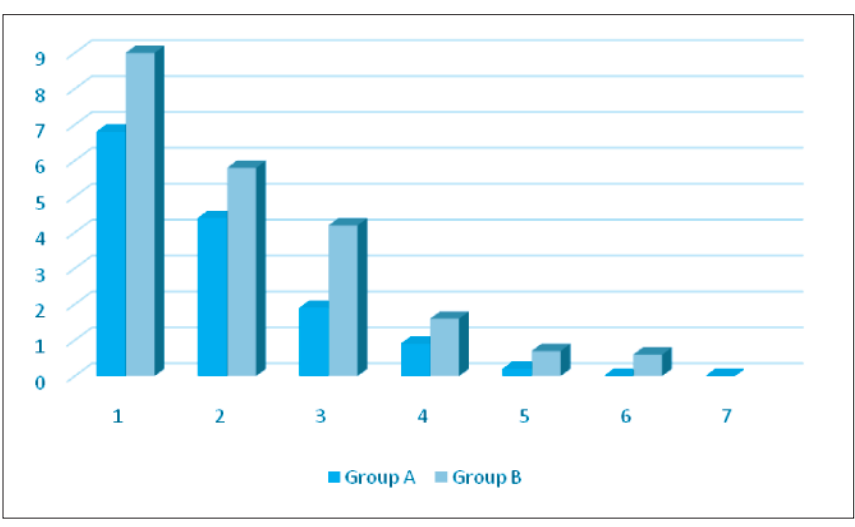

Figure 1: Frequency of diarrhea,time/day

The mean frequency of diarrhea before treatment was 10.93 times/day in the combination group, and 12.25 times/day in the zinc group. The duration of diarrhea before treatment was 52.8 hours (2.2 days) in the combination group and 57.6 hours $(2.4$ days) in the zinc group.

Table II : Duration of diarrhea and length of hospital stay after treatment

\begin{tabular}{lcccc} 
Characteristics & Group A & Group B & CI & p value \\
$\begin{array}{l}\text { Duration of } \\
\text { diarrhea (hours) }\end{array}$ & $56.4 \pm 21.36$ & $70.8 \pm 22.8$ & -23.04 to -5.28 & 0.002 \\
$\begin{array}{l}\text { Length of hospital } \\
\text { stay (hours) }\end{array}$ & $68.16 \pm 23.76$ & $83.04 \pm 26.16$ & -24.72 to -4.80 & 0.004 \\
\hline
\end{tabular}

\section{DISCUSSION}

During treatment, there were significant differences in diarrheal frequency in the two groups from the first to fourth days. No parents or caregivers in either group reported recurrent diarrhea or complained of toxicity or side effects often associated with zinc and probiotics.

In this study, the mean age of children with acute diarrhea was $11.88 \pm 6.5$ months in the combination group and $11.79 \pm 5.98$ months in the zinc group. Previous epidemiological studies found that children with acute diarrhea were aged 0 to 12 months ${ }^{13}$. There was another study done by them where mean age was $19.18 \pm 12.78$ months $\& 20.02 \pm 14.02$ months in case $\&$ control group respectively ${ }^{14}$. There are more male in each group ( $63.5 \%$ vs $56.4 \%$ ). One study of diarrhea in hospitalized children aged 0 to 36 months found that the incidence of acute diarrhea was higher in boys, but did not discuss possible theories for this occurence. The incidence of diarrhea is more in between 6-24 month of age which is $40(76.9 \%)$ in group A and $37(67.3 \%)$ in group B respectively. Epidemiological study found that children with acute diarrhea caused by rotavirus were aged 0-12 month ${ }^{15,16}$. The number of diarrhea patient in between 3-6 month is 7(13.5\%) in group A and 10(18.2\%) in group B respectively, but mostly around $75 \%$ are associated with mixed feeding. It is also observed that diarrhoea incidence is high who drink supply water and low socioeconomic group. In our study only $21.2 \%$ mothers in Group A and $14.4 \%$ mother in Group B does not know how to prepare ORS, one of most important risk factor for electrolyte imbalance (hypernatremic and hyponatremic dehydration) which increase the mortality and morbidity in AWD in developing countries like Bangladesh. Before admission, in this study, $10(20 \%) 40(80 \%)$ children in group A and 16 (29.1\%), 34(61.8\%) children in group B had no, and some dehydration respectively. Similar study done by Erdogan et al. where shown that $48 \%$ \& $52 \%$ children in probiotic 1 (Saccharomyces boulardii) group, 44\% \& 56\% in probiotic 2 (Bifidobacterium lactis) and $52 \% \& 48 \%$ in control group (only oral rehydration) had no \& some dehydration that is more or less similar to this study ${ }^{17}$.

Mean duration of diarrhea before treatment was $58.4 \pm 18.67$ hours in combination group and $52 \pm 23.5$ hours in zinc in our study. Aggarwal et al reported mean duration of diarrhea before treatment was $52.08 \pm 30.48$ hours in probiotic group \& 59.52 \pm 30.72 hours in control group. Duration of diarrhea before treatment was shorter than Aggarwal et al study ${ }^{17}$.

In present study on an average each patient passed $10.93 \pm 10.27$ times of stool before treatment among the group A and $12.25 \pm 10.35$ times of stool in group B. In this study, length of hospital stay was shorter in combination group than zinc group which is similar to Hatta et al study ${ }^{16}$.

Similar studies conducted by Billoo et al. Aggarwal et al. Azim et al also reported that probiotics improved consistency of stool $^{17,18}$.

Length of hospital stay cannot be used as an indicator of therapeutic success due to many other factors that affect the length of patient hospitalization, such as time delays in hospital discharge caused by the parents' requests or payment issues. In my study zinc-probiotics group complete remission was achieved within $56.4 \pm 21.36$ hours which was faster (p-0.002) than that of zinc alone group (70.8 \pm 22.8 hours). This study also showed a significant improvement in duration of hospital stay (68.16 \pm 23.76 hours VS $83.04 \pm 26.16$ hours) in patients who were given in combination therapy.

\section{LIMITATION}

Limitation of this study were that the etiology of diarrhea was unknown and study was only admitted patients in the pediatric wards were enrolled which leads to selection bias.

\section{CONCLUSION}

World Health Organization (WHO) does not recommended the use of probiotic in diarrhea, but in our country the use of probiotic is increasing day by day in acute watery diarrhoeas. By doing this study we can conclude that, combination of probiotics \& zinc therapy is more effective in reducing the severity of acute diarrhea than zinc therapy alone.

\section{FUNDING}

This study has been conducted by the financial assistant of Chattogram Maa-O-Shishu Hospital Medical College.

\section{DISCLOSURE}

All the authors declared no competing interest. 


\section{REFERENCES}

1. Liu L, Johnson HL, Cousens S, Perin J, Scott S, Lawn JE, Rudan I, Campbell H, Cibulskis R, Li M. et al.Global, regional, and national causes of child mortality: An updated systematic analysis for 2010 with time trends since 2000. Lancet. 2012;379(9832):2151-2161.

2. WHO/UNICEF. Joint statement: Clinical management of acute diarrhea (WHO/FCH/CAH/04.07) Geneva \& New York: World Health Organization, Department of Child and Adolescent Health and Development and the United Nations Children's Fund, Programme Division. 2004.

3. Allen SJ, Martinez EG, Gregorio GV, Dans LF. Probiotics for treating acute infectious diarrhoea. Cochrane Database Syst Rev. 2010;CD003048.

4. Macfarlane GT, Cummings JH. Probiotics and prebiotics: Can regulating the activities of intestinal bacteria benefit health? BMJ. 1999;318(7189):999-1003.

5. Vanderhoof JA, Young RJ. Use of probiotics in childhood gastrointestinal disorders. J Pediatr Gastroenterol Nutr. 1998;27(3):323-332.

6. Vehrman RF, Kliegman RM, Jenson HB: Nelson Textbook of pediatrics.20 th ed. Philadelphia, Saunders. 2015; 340: 1872-1874.

7. Isolauri E. Probiotics for infectious diarrhoea. Gut. 2003;52:436-437.

8. Davidson GP, Butler RN. Probiotics in intestinal disorders. Curr Opin Pediatr 2000;12:477-481.

9. Sunil Sazawal, Robert E Black, Maharaj K Bhan, Nita Bhandari, Anju Sinha, Sanju Jalla. Zinc supplementation in young children with acute diarrhoea in India. N Engl J Med. 1995;333:839-844.

10. Zulfiqar A Bhutta, Sheila M Bird, Robert E Black, Kenneth H Brown, Julie Meeks Gardner, Adi Hidayat, et al. Therapeutic effects of oral zinc in acute and persistent diarrhoea in children in developing countries: Pooled analysis of randomized controlled trials. Am J Clin Nutr. 2000;72:1516-1522.

11. ICDDRB. Zinc supplementation for the treatment of diarrhea moving from research to practice. 2014. Available from: http://www.mostproject.org

12. WHO treatment of diarrhea, a manual of physians and other senior health workers, $4^{\text {th }}$ revision, Geneva: WHO press. 2005.

13. Nguyen TV,Le Van P, Le Huy C, Weintraub A, Diarrhea caused by rotavirus in children less than 5 years of age in Hanoi, Vietnam. J Clin Microbiol. 2004;42:5745-5750.

14. khan SA, Ahmed A,Khalid SM, Diarrhea due to rotavirus and probability of sewage contamination. J Islamic Acad SCI. 1992;5:142-144.

15. Erdogan O, Tanyeri B, Torun E, Gonullu E, Arslan H, Erenberk U and Oktem F, 2012. Clinical Study The Comparition of the Efficacy of Two Different Probiotics in Rotavirus Gastroenteritis in Children. Hindawi Publishing Corporation; Journal of Tropical Medicine, Article ID787240. 2012;5. doi:10.1155/2012/787240.

16. Hatta M, Supriatmo, Ali M, Sinuhaji AB, Hasibuan B, Nasution FL. Comparison of zinc-probiotic combination therapy to zinc therapy alone in reducing the severity of acute diarrhea. Paediatrica Indonesia.2011; 51(1):1-6.

17. Aggarwal S, Upadhyay A, Shah D, Teotia N, Agarwal A \& JaiswalV. Lactobacillus GG for treatment of acute childhood diarrhea: An open labelled, randomized controlled trial. Indian J Med Res.2014; 139: 379-385.

18. Billoo AG, Memon MA, Khaskheli SA, Murtaza G, Iqbal K, Shekhani M S, Siddiqi A Q. Role of a probiotic (Saccharomyces boulardii ) in management and prevention of diarrhoea. World J Gastroenterol. 2006; 12(28): 4557-4560. 